\title{
Nature of the mucosal changes associated with malignant neoplasms in the small intestine
}

\author{
F. D. LEE \\ From the University Department of Pathology, Western Infirmary, \\ Glasgow
}

EDITORIAL COMMENT The author of this paper has again brought up the much discussed problem of malignant disease of the small bowel and its relation to idiopathic steatorrhoea. Whilst agreeing that idiopathic steatorrhoea can be complicated by malignant disease he also feels that malignant disease, and particularly small bowel lymphoma, can produce a mucosal abnormality similar to that found in idiopathic steatorrhoea.

It has long been recognized that malabsorption may be associated with lymphoid tumours in the small intestine (Fairley and Mackie, 1937) but it is only recently that it has been suggested that such tumours may arise as a complication of the primary malabsorptive disorders ${ }^{1}$ (Gough, Read, and Naish, 1962). The evidence for this is almost entirely clinical since it has yet to be clearly demonstrated that the mucosal abnormalities, which represent the only distinctive pathological feature of the primary malabsorptive disorders, have been present for a significant period before the onset of tumour growth, although they have been demonstrated in the resected small bowel following operation (Spracklen, for Tonkin, 1963) and in intestinal biopsies taken seven months before operation for tumour (Gough et al., 1962). It is possible that an alteration in mucosal pattern in the small bowel may be a response to the presence of a gross lesion, a situation comparable to the 'zonal gastritis' described in relation to chronic peptic ulcer and carcinoma in the stomach (Joske, Finckh, and Wood, 1955). If this were true, one might expect that mucosal abnormalities would be found in association with any gross tumour of the small bowel regardless of its histogenesis.

The histopathology of the small intestine in a series of resected malignant lymphoid tumours has thus been compared with a closely matched series of small-bowel adenocarcinomata. The marked difference in the nature, severity, and extent of the mucosal changes observed between the two groups would

\footnotetext{
1 This term is applied to the three diseases, coeliac disease, idiopathic steatorrhoea, and tropical sprue, as suggested by Girdwood, Delamore, and Williams (1961).
}

indicate that additional factors are operating in association with the lymphoid tumours to produce mucosal abnormality. It is possible that a preexisting malabsorptive disorder may have accounted for the severe mucosal changes observed in one patient who had a reticulosarcoma of the small bowel resected following a seven-year history of malabsorption, and also in one patient with adenocarcinoma of the jejunum. It is suggested, however, that in the majority of instances the lymphoid neoplasm is itself responsible for the mucosal abnormalities.

\section{MATERIALS AND METHODS}

A survey of all the surgically resected primary malignant tumours of the small intestine of lymphoid or adenocarcinomatous type in the files of the Pathology Department of the Western Infirmary, Glasgow for the years 1953-64 was undertaken. Those cases in which autolytic change or inadequate material obviated adequate mucosal assessment were rejected, leaving nine cases available for study in each group. Where necessary blocks were re-cut and stained to provide satisfactory orientation of the intestinal mucosa and whenever possible extra blocks were taken to produce further information with regard to the extent of mucosal abnormality. Special stains were only employed to enable individual tumours to be correctly classified within each group.

The clinical records and operation notes were reviewed in each case, particular attention being paid to any feature in the past history in any way suggestive of intestinal malabsorption. The relevant clinical findings in each group are recorded in the table, and are summarized as follows:-

I MALIGNANT LYMPHOID NEOPLASM Of the nine patients in this group, seven were males and two females, the 
average age at operation being 50 years with a range of 32 to 70 years. The average duration of symptoms before operation was six months with a range of one to 18 months.

Perforation was the mode of presentation in seven cases, this being a not uncommon feature of these tumours (Irvine and Johnstone, 1955). Intestinal obstruction was present in three cases, being associated with perforation in case 3 and with intussusception in case 8 . Multiple tumours were noted in cases 4,5 , and 9 . The tumour was found in the ileum in four cases, in the jejunum in three, and in the 'upper small bowel' in case 9. The site of tumour was not stated in case 2 .

Only in case 9 was malabsorption demonstrated before operation. This patient, a 51-year-old male, had two thickened and adherent segments of upper small bowel resected following perforation of the proximal segment. Both pathological specimens revealed multiple infiltrating tumours which had penetrated the bowel wall to become adherent to adjacent loops of bowel. The patient gave a two-month history of intermittent abdominal pain located in the left iliac fossa. He also had a seven-year history of weight loss and diarrhoea with pale, offensive stools; and five years before operation, frank malabsorption with steatorrhoea and severe megaloblastic anaemia had been demonstrated. The anaemia was controlled with folic acid and vitamin $\mathbf{B}_{12}$, but a sixmonth trial period on a gluten-free diet failed to induce a remission of the malabsorptive defect. Intestinal biopsy was not carried out at the time of the initial investigation, but subtotal villous atrophy of the intestinal mucosa is noted histologically throughout both resected segments of small bowel.

In case 5 a hypochromic anaemia refractory to oral iron therapy was observed five years before the onset of symptoms clearly attributable to tumour growth. Malabsorption could not, however, be confirmed clinically in this case, nor was there a history of malabsorption in any of the remaining seven cases.

Although all the tumours in this group are considered to be primary in the small bowel, it is of interest that in case 3 a polypoid lymphosarcoma had been removed from the posterior nares nine months before resection of the intestinal neoplasm, which could thus have been of metastatic origin. Since the patient is, however, alive and well nine years after operation it is possible that the intestinal tumour was in fact an independent primary growth.

II ADENOCARCINOMA There were six males and three females in this group, and the average age at operation was 57 years with a range of 29 to 74 years. The average duration of symptoms was 10 months, varying from six weeks to two years. Intestinal obstruction was the usual mode of presentation, being present in five cases; in three cases diarrhoea, weight loss, and hypochromic anaemia with or without frank melaena were the presenting symptoms, and in case 18 the patient gave a five-year history of post-prandial epigastric discomfort, although frankly obstructive features with vomiting and marked duodenal dilatation were observed before operation. The tumour was solitary in every case (although

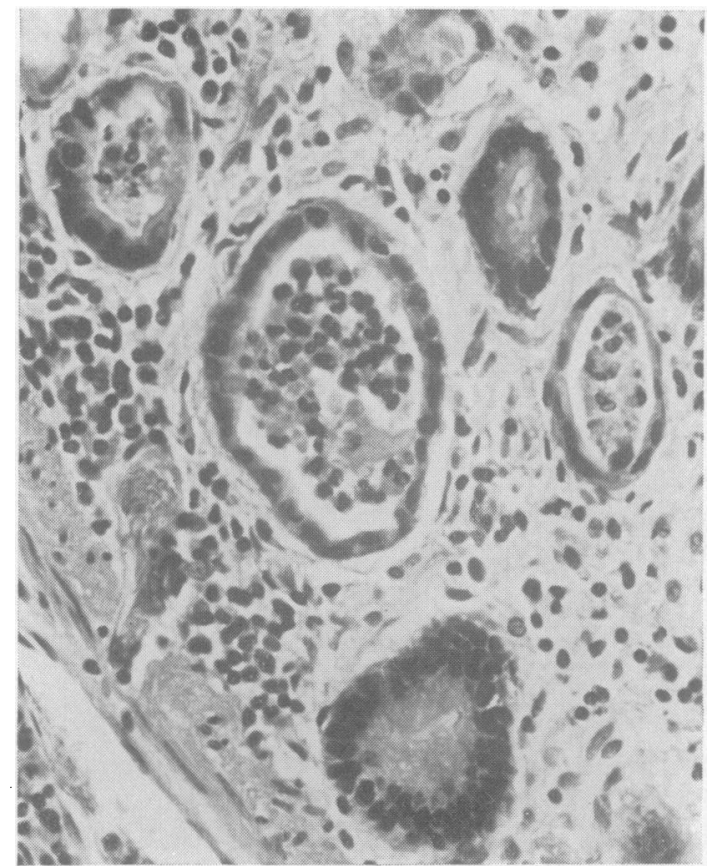

FIG. 1. Lymphosarcoma of ileum (case 1). Crypt abscess formation in the mucosa close to the tumour. Haemalumeosin $\times 396$.

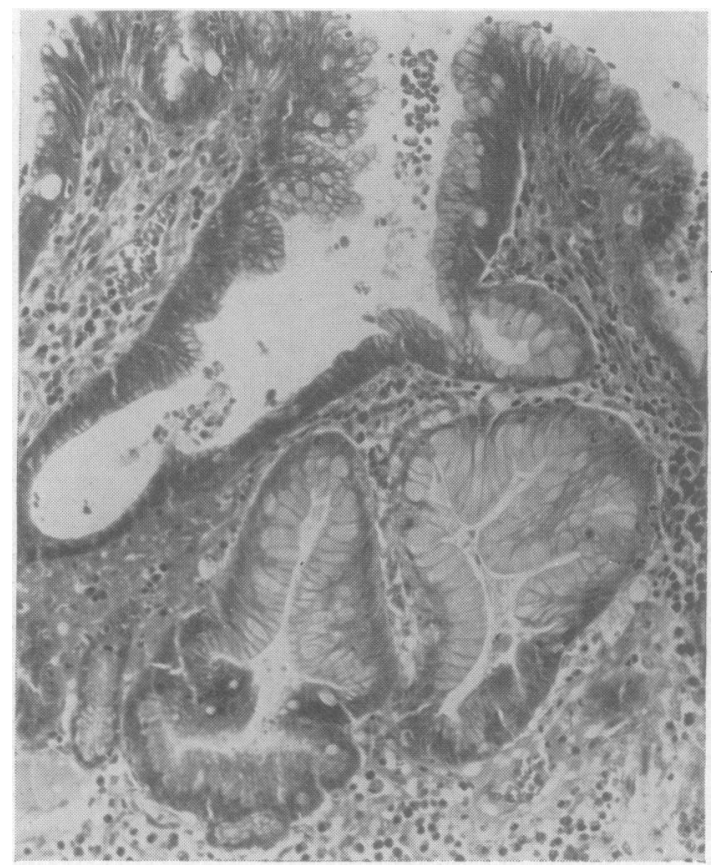

FIG. 2. Lymphosarcoma of jejunum (case 7). Pyloric metaplasia in the intestinal mucosa overlying the tumour. Haemalum-eosin $\times 165$. 
associated with an independent primary carcinoma of the colon in case 16). The tumour was found in the ileum in four cases and in the jejunum in four; the site was not recorded in case 10 . There was no evidence of malabsorption in the past history in any of the cases.

THE ASSESSMENT OF MUCOSAL ABNORMALITY The mucosal changes in any individual case were referred to as 'partial' or 'subtotal' villous atrophy if they could not be distinguished histologically from those described in the primary malabsorptive disorders (Shiner and Doniach, 1960); and if they could be demonstrated in all parts of the intestinal mucosa whether close to or distant from the tumour site. In the evaluation of these changes, particular attention was paid to the presence of abnormalities in the surface epithelium, and to increased plasma-cell infiltration in the lamina propria.

The mucosa was designated as 'normal' in all cases in which the mucosal pattern was within normal limits in any of the blocks taken, even if the mucosa close to the tumour exhibited abnormalities. The term 'non-specific zonal inflammation' has been applied to strictly localized changes which are characterized by intense mucosal leucocytic infiltration, in which lymphocytes predominate, occasional crypt abscesses with or without frank ulceration (Fig. 1) and metaplasia of pyloric type (Fig. 2). The mucosal villi vary in appearance from being thickened and enlarged to presenting features resembling villous atrophy, although of strictly localized type. Conversely some of the features of this 'zonal' inflammation may be superimposed on a generalized villous atrophy close to the tumour site (Fig. 2).
RESULTS

The incidence of mucosal abnormality observed in the two forms of malignant tumour is recorded in the Table. In the adenocarcinoma group, the mucosal pattern is considered to be essentially normal, with or without zonal inflammation, in seven cases. The appearances in case 18 are, however, of considerable interest in that subtotal villous atrophy of the mucosa is observed both histologically (and with the dissecting microscope) throughout the entire resected $15.0 \mathrm{~cm}$. segment of jejunum. In case 14, changes of a generalized nature, corresponding to a mild partial villous atrophy of the ileal mucosa, are seen.

On the other hand, in only two cases in the lymphoid tumour group could the mucosa be considered normal, and in one of these (case 3) it may be doubted whether the tumour was primary in the small intestine. In the other six cases, generalized villous atrophy varying in severity from the partial villous atrophy in case 7 (Fig. 3) to the frank subtotal villous atrophy in case 4 (Fig. 4) can be demonstrated. In case 9, as already indicated, the intestinal mucosa from two separate resections of the upper small bowel shows subtotal villous atrophy throughout.

The irregular but widespread nature of the 'atrophic' process is revealed in case 5, in which multiple sections were taken from two separate

TABLE

INCIDENCE OF MUCOSAL ABNORMALITY IN TWO TYPES OF MALIGNANT TUMOUR

\begin{tabular}{|c|c|c|c|c|c|c|c|c|c|}
\hline $\begin{array}{l}\text { Case } \\
\text { No. }\end{array}$ & Sex & Age & Mode of Presentation & $\begin{array}{l}\text { Duration } \\
\text { of } \\
\text { Symptoms }\end{array}$ & $\begin{array}{l}\text { History of } \\
\text { Malabsorption }\end{array}$ & Tumour Type & $\begin{array}{l}\text { Site of } \\
\text { Tumour }\end{array}$ & $\begin{array}{l}\text { Small Intestinal } \\
\text { Mucosal Pattern }\end{array}$ & $\begin{array}{l}\text { Zonal } \\
\text { Inflam- } \\
\text { mation }\end{array}$ \\
\hline 1 & $\mathbf{M}$ & 32 & Perforation & 21 wk. & None & Lymphosarcoma ${ }^{1}$ & Ileum & Subtotal villous atrophy & ++ \\
\hline 2 & $\mathbf{F}$ & 70 & Perforation & $18 \mathrm{mth}$. & None & Reticulosarcoma & Small bowel & Partial villous atrophy & + \\
\hline 3 & $\mathbf{M}$ & 51 & Perforation and obstruction & 20 wk. & None & Lymphosarcoma & Ileum & Normal & $++t$ \\
\hline 4 & $\mathbf{M}$ & 55 & Perforation (multiple) & $3 \mathrm{mth}$. & None & Reticulosarcoma & $\begin{array}{l}\text { Jejunum } \\
\text { (multiple) }\end{array}$ & Subtotal villous atrophy & - \\
\hline 5 & $\mathbf{M}$ & 50 & Perforation & $9 \mathrm{mth}$. & $\begin{array}{l}\text { Five-year history } \\
\text { of refractory } \\
\text { hypochromic } \\
\text { anaemia }\end{array}$ & Lymphosarcoma & $\begin{array}{l}\text { Ileum } \\
\text { (multiple) }\end{array}$ & $\begin{array}{l}\text { Subtotal villous atrophy } \\
\text { (irregular) }\end{array}$ & ++ \\
\hline 6 & $\mathbf{F}$ & 49 & Perforation & 12 wk. & None & Reticulosarcoma & Jejunum & Partial villous atrophy & + \\
\hline 7 & $\mathbf{M}$ & 46 & Intestinal obstruction & 7 wk. & None & Lymphosarcoma & Jejunum & Partial villous atrophy & ++ \\
\hline 8 & $\mathbf{M}$ & 46 & Intussusception & 4 wk. & None & Lymphosarcoma $^{1}$ & ${ }^{1}$ Ileum & Normal & + \\
\hline 9 & $\mathbf{M}$ & 51 & Perforation & 2 mth. & $\begin{array}{l}\text { Seven-year history } \\
\text { of steatorrhoea } \\
\text { and megaloblastic } \\
\text { anaemia }\end{array}$ & Reticulosarcoma & $\begin{array}{l}\text { 'Upper small } \\
\text { bowel' }\end{array}$ & Subtotal villous atrophy & ++ \\
\hline 10 & $\mathbf{M}$ & 29 & $\begin{array}{l}\text { Diarrhoea, melaena, and } \\
\text { weight loss }\end{array}$ & $2 \mathrm{yr}$. & None & Adenocarcinoma & Small bowel & Normal & $++t$ \\
\hline 11 & $\mathbf{F}$ & 56 & Intestinal obstruction & 6 wk. & None & Adenocarcinoma & Ileum & No & ++ \\
\hline 12 & $\mathbf{M}$ & 74 & $\begin{array}{l}\text { Diarrhoea, hypochromic } \\
\text { anaemia, weight loss }\end{array}$ & $1 \mathrm{yr}$ & None & Adenocarcinoma & Jejunum & Normal & + \\
\hline 13 & $\mathbf{F}$ & 61 & Intestinal obstruction & 6 wk. & None & Adenocarcinoma & Jejunum & Normal & + \\
\hline 14 & $\mathbf{M}$ & 65 & Intestinal obstruction & 7 wk. & None & Adenocarcinoma & Ileum & Partial villous atrophy & + \\
\hline 15 & F & 67 & Intestinal obstruction & Uncertain & None known & Adenocarcinoma & Ileum & Normal & - \\
\hline 16 & $\mathbf{M}$ & 37 & Intestinal obstruction & 6 mth. & None & Adenocarcinoma & Jejunum & Normal & + \\
\hline 17 & $\mathbf{M}$ & 69 & $\begin{array}{l}\text { Diarrhoea, vomiting, } \\
\text { hypochromic anaemia }\end{array}$ & 2 yr. & None & Adenocarcinoma & Ileum & Normal & ++ \\
\hline 18 & $\mathbf{M}$ & 53 & Epigastric pain (intestinal & 5 yr. & None & Adenocarcinoma & Jejunum & Subtotal villous atrophy & ++ \\
\hline
\end{tabular}

${ }^{1}$ Marked plasma cell differentiation 


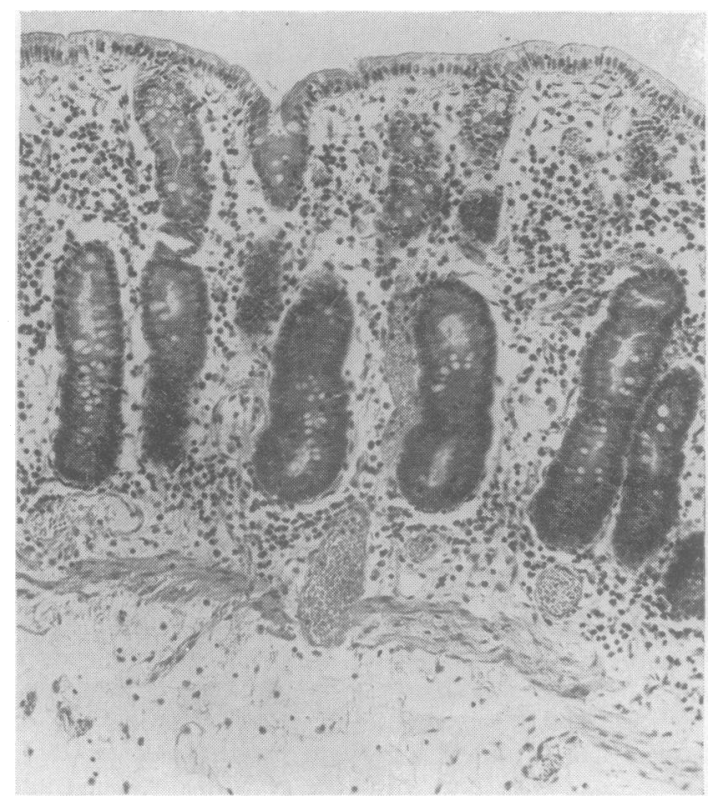

FIG. 4

FIG. 3. Lymphosarcoma of jejunum (case 7). Partial villous atrophy of the mucosa. The average villous height is $290 \mu$, and the surface epithelium is markedly abnormal. Haemalum-eosin $\times 150$.

FIG. 4. Reticulosarcoma of jejunum (case 4). Subtotal villous atrophy of the mucosa. Haemalum-eosin $\times 99$.

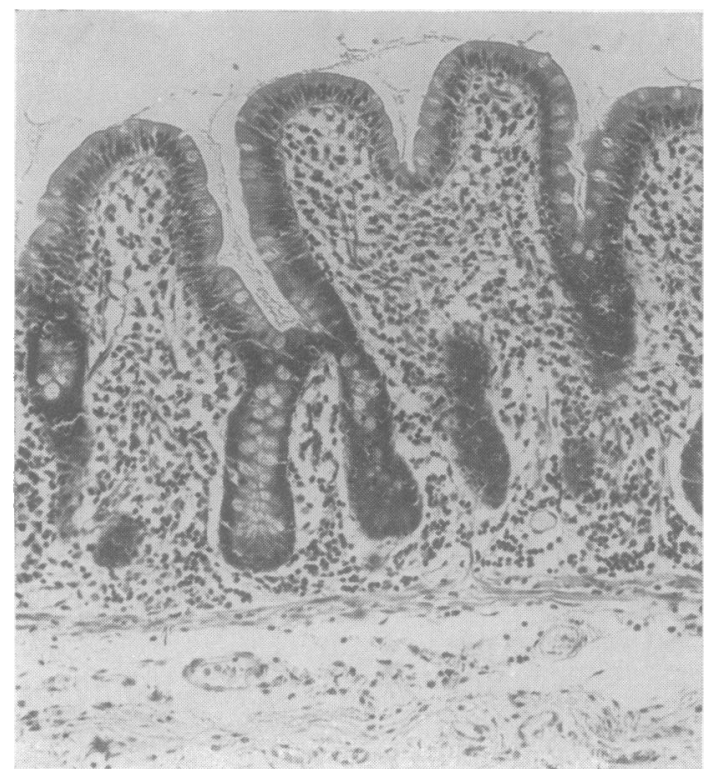

FIG. 5

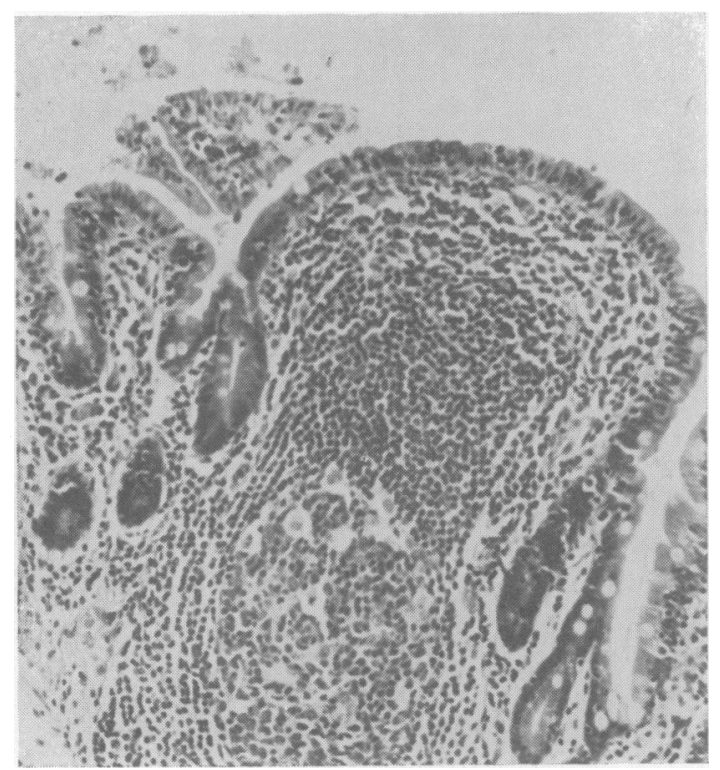

FIG. 6

FIG. 5. Reticulosarcoma of jejunum (case 6). Partial villous atrophy of the mucosa undergoing transition to subtotal atrophy. The average height is $295 \mu$. Haemalum-eosin $\times 126$.

FIG. 6. Lymphosarcoma of jejunum (case 7). Degenerative changes in the surface epithelium overlying a lymphoid follicle. Haemalum-eosin $\times 146$. 


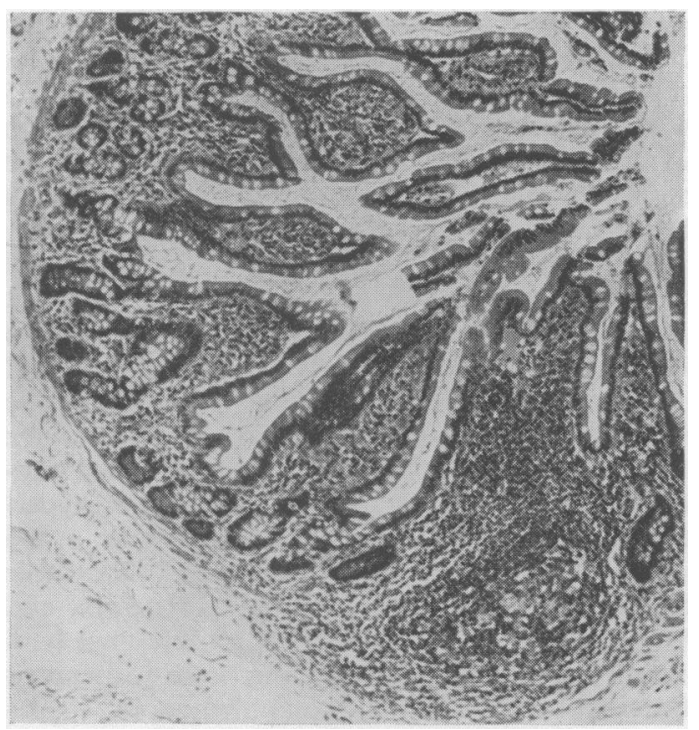

FIG. 7. Lymphosarcoma of ileum (case 3). Fibrous thickening of the mucosal villi with the formation of bizarre shapes, associated with marked submucosal oedema. Haemalum-eosin $\times 80$.

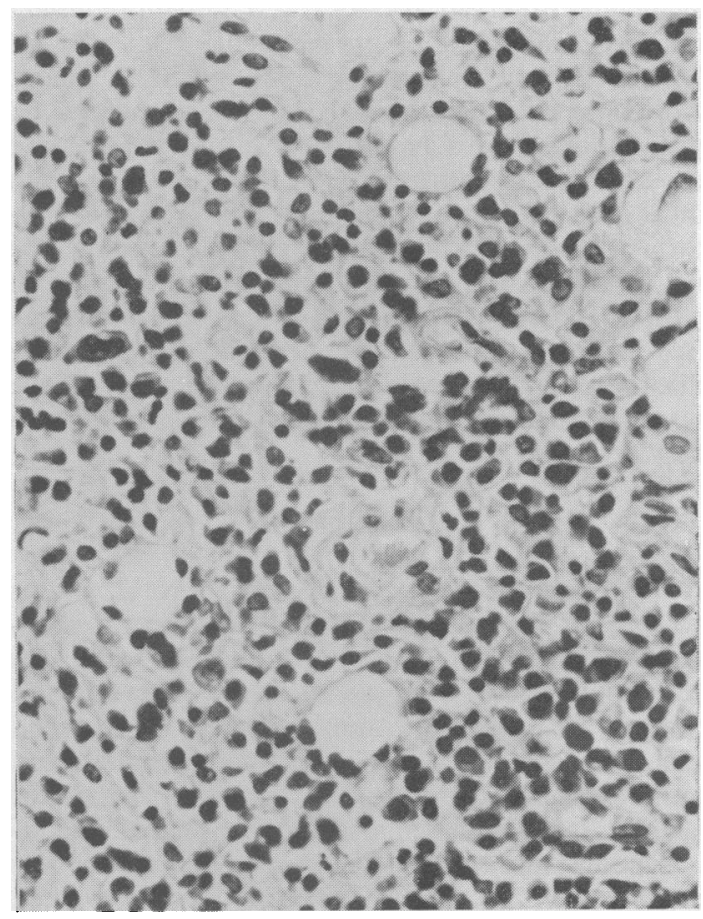

FIG. 8. Lymphosarcoma of ileum (case 1). Atypical plasma-cell differentiation in the tumour. Haemalum-eosin $\times 396$. ileal resections. Variations in the mucosal pattern from partial to subtotal villous atrophy are also noted in the jejunum in case 6 (Fig. 5), in which numerous sections were taken far removed from the tumour site. A curious feature, observed in two cases (6 and 7), is the presence of marked abnormality of the surface epithelium overlying lymphoid aggregates in areas quite separate from the main tumour mass (Fig. 6).

In cases 3 and 10 the intestinal mucosa shows a peculiar abnormality in which the villi exhibit bizarre shapes due to localized fibrous thickening of the lamina propria (Fig. 7). In both instances intense mucosal oedema, probably due to lymphatic occlusion by tumour growth, was considered to be responsible for the villous abnormality, which is thus regarded as a variant of the zonal type of inflammation.

Within the group of malignant lymphoid neoplasms, the tumour is classified as reticulosarcoma in four cases and lymphosarcoma in three cases. The remaining two cases are less readily classified. The tumour in case 8 is predominantly a lymphosarcoma but shows marked plasma-cell differentiation; this feature is also prominent in case 1 in which the neoplasm is composed almost entirely of plasma cells or their precursors (Fig. 8). In neither case, however, was there evidence of generalized myelomatosis, nor could plasma-cell differentiation in a lymphoid neoplasm be correlated with the presence of mucosal atrophy.

\section{DISCUSSION}

This comparison between the two major groups of primary malignant tumours in the small intestine was undertaken initially to determine whether the mucosal changes associated with such tumours could be attributed solely to non-specific local factors such as intestinal obstruction, stasis, oedema, and secondary infection of the bowel wall in the vicinity of the tumour. If this were the case the nature and extent of these changes would not be related so much to the histogenesis of the tumour as to its mechanical effects, and one would expect them to be more marked in the adenocarcinoma group, in which intestinal obstruction was a more prominent clinical feature. Whilst 'zonal' changes, no doubt due to mechanical factors, are observed in both groups, the high incidence of generalized villous atrophy in the group of lymphoid tumours cannot be explained readily on this basis. Such widespread mucosal abnormalities could, however, take origin either from a pre-existing malabsorptive disorder such as idiopathic steatorrhoea or be 
related to the presence of tumour in some less direct way.

Gough et al. (1962) reported three cases which indicated that intestinal reticulosis may develop as a complication of idiopathic steatorrhoea, and Spracklen, for Tonkin (1963), described a further case supporting this conclusion. On the other hand, Eakins, Fulton, and Hadden (1964) drew attention to the relatively short duration of clinically recognized malabsorption in many cases of intestinal reticulosis and considered that in some cases at least the tumour itself is responsible for malabsorption. The possibility cannot be excluded therefore that, in those cases of intestinal reticulosis in which malabsorption is due to a pre-existing primary malabsorptive disorder, the association is fortuitous. If this were true, it might be expected that adenocarcinoma would also complicate idiopathic steatorrhoea on occasion, since lymphoid neoplasms comprise only $50 \%$ of primary malignant tumours in the small bowel (Skrimshire, 1955). This appears to be the case. Joske (1960) described a case of jejunal adenocarcinoma associated with 'atrophic jejunitis' and malabsorption and referred to a similar instance in the Case Records of the Massachusetts General Hospital (1958). Girdwood et al. (1961) described the coexistence of subtotal villous atrophy in a jejunal biopsy, malabsorption, and an anaplastic carcinoma $70 \mathrm{~cm}$. below the duodeno-jejunal junction; and Moertel and Hargraves (1961) have also reported a case in which jejunal adenocarcinoma complicated long-standing malabsorption, and was associated with villous atrophy of the jejunal mucosa. It may well be that case 18 in my series represents a fifth example of jejunal adenocarcinoma complicating idiopathic steatorrhoea in a clinically asymptomatic phase; the mucosal abnormalities in this case certainly form a striking contrast to the relatively normal mucosa observed in the other cases of small-bowel carcinoma. It is also possible that in case 9 , in which reticulosarcoma of the small bowel was associated with a seven-year history of malabsorption and subtotal villous atrophy of the intestinal mucosa, a similar situation may pertain. Nevertheless, although it cannot be doubted that malignant tumours may complicate one or other of the primary malabsorptive disorders, this association does not seem to provide a satisfactory explanation for the presence of mucosal atrophy in six out of the eight other random selected cases of intestinal lymphoid tumour in the present series. Although the absence of clinically recognized malabsorption in these cases is of doubtful significance, it accords with general experience of intestinal lymphoid neoplasms; malabsorption was not recorded either in the series of cases reported by Skrimshire (1955) or in the large series of cases reviewed by Rosenberg, Diamond, Jaslowitz, and Craver (1961). It may be added that subtotal villous atrophy of the ileal mucosa, observed in cases 1 and 5 in my series, would be an improbable finding in asymptomatic sprue, since even in active cases the lesions are said to be less severe in the ileum than in the proximal small bowel (Rubin, 1960).

The alternative possibility that an intestinal tumour may in some indirect way bring about widespread mucosal abnormality must therefore be seriously considered. It is well recognized that tumours originating in lymphoid tissue may give rise to immunological disturbances, auto-immune haemolytic anaemia being perhaps the most outstanding example (Dacie, 1962). Since a hypersensitivity mechanism may be of importance in the pathogenesis of coeliac disease and idiopathic steatorrhoea (see Taylor, Thomson, Truelove, and Wright, 1961), it is possible that an intestinal lymphoid tumour (perhaps reflecting more widespread abnormality of the intestinal lymphoid tissue) could by a similar mechanism bring about a comparable mucosal abnormality. The development of clinical malabsorption would then depend upon the extent or site of the mucosal damage. The relationship between epithelial abnormality and lymphoid aggregates observed in cases 6 and 7 might represent the morphological expression of the role of lymphoid tissue in bringing about mucosal damage. Although this hypothesis is largely speculative, it may be capable of being subjected to clinical and experimental investigation. The relationship between intestinal neoplasms and the malabsorption syndrome, however, is likely to be complex and may be finally settled only by the long term follow-up of patients proven by intestinal biopsy to be suffering from one or other of the primary malabsorptive disorders; and by careful pathological study of the resected tumours and of the environment in which they arise.

\section{SUMMARY}

A high incidence of partial or subtotal villous atrophy of the intestinal mucosa has been demonstrated in a series of resected primary malignant lymphoid tumours of the small bowel. These mucosal changes are much less common in a closely-matched series of small-intestinal adenocarcinomata, and cannot readily be attributed to local mechanical factors. In two patients, one with jejunal adenocarcinoma and one with reticulosarcoma of the small bowel, the mucosal changes may have been due to a pre-existing primary malabsorptive disorder. In the majority of cases, however, it is postulated that the mucosal abnormalities are brought about 
by the malignant lymphoid tumour, possibly as a result of immunological disturbances.

I wish to thank Mr. D. B. Brown, Professor A. W. Kay, and Mr. A. B. Kerr for permission to study their patients. My thanks are also due to Mr. N. Russell for his technical assistance, and to Mr. G. Kerr for taking the photomicrographs.

\section{REFERENCES}

Case records of the Massachusetts General Hospital (1958). Case 44362. New Engl. J. Med., 259, 491-495.

Dacie, J. V. (1962). The Haemolytic Anaemias, Congenital and Acquired, part 2-The Auto-Immune Haemolytic Anaemias, 2nd ed. Churchill, London.

Eakins, D., Fulton, T., and Hadden, D. R. (1964). Reticulum cell sarcoma of the small bowel and steatorrhoea. Gut, 5, 315-323.

Fairley, N. H., and Mackie, F. P. (1937). The clinical and biochemical syndrome in lymphadenoma and allied diseases involving the mesenteric lymph glands. Brit. med. J., 1, 375-380.

Girdwood, R. H., Delamore, I. W., and Williams, A. W. (1961). Jejunal biopsy in malabsorptive disorders of the adult. Ibid., 1, 319-323.

Gough, K. R., Read, A. E., and Naish, J. M. (1962). Intestinal reticulosis as a complication of idiopathic steatorrhoea. Gut, 3, 232-239.
Irvine, W. T., and Johnstone, J. M. (1955). Lymphosarcoma of the small intestine, with special reference to perforating tumours. Brit J. Surg., 42, 611-618.

Joske, R. A. (1960). Primary carcinoma of the jejunum with atrophic jejunitis and intestinal malabsorption. Gastroenterology, 38, 811-816.

—, Finckh, E. S., and Wood, I. J. (1955). Gastric biopsy. A study of 1,000 consecutive successful gastric biopsies. Quart. J. Med., 24, 269-294.

Moertel, C. G., and Hargraves, M. M. (1961). Coexistence of adenocarcinoma of the jejunum and nontropical sprue. J. Amer. med. Ass., 176, 612-614.

Rosenberg, S. A., Diamond, H. D., Jaslowitz, B., and Craver, L. F., (1961). Lymphosarcoma: a review of 1,269 cases. Medicine (Baltimore), 40, 31-84.

Rubin, C. E. (1960). Celiac disease and idiopathic sprue. Some reflections on reversibility, gluten, and the intestine. Gastroenterology, 39, 260-261.

Shiner, M., and Doniach, I. (1960). Histopathologic studies in steatorrhoea. Ibid., 38, 419-440.

Skrimshire, J. F. P. (1955). Lymphoma of the stomach and intestine. Quart. J. Med., 24, 203-214.

Spracklen, F., for Tonkin, R. D. (1963). Reticulosis of the small bowel as a late complication of idiopathic steatorrhoea. Proc. roy. Soc. Med., 56, 167-168.

Taylor, K. B., Thomson, D. L., Truelove, S. C., and Wright, R. (1961). An immunological study of coeliac disease and idiopathic steatorrhoea: serological reactions to gluten and milk proteins. Brit. med. J., 2, 1727-1731. 